This is a postprint of:

Soissons, L.M., Li, B., Han, Q. van Katwijk, M.M., Ysebaert, T., Herman, P.M.J. \& Bouma, T.J. (2016). Understanding seagrass resilience in temperate systems: the importance of timing of the disturbance. Ecological Indicators, 66, 190-196.

Published version: $\underline{\mathrm{dx} . \text { doi.org/10.1016/i.ecolind.2016.01.030 }}$

Link NIOZ Repository: $\underline{w w w . v l i z . b e / n l / i m i s ? m o d u l e=r e f \& r e f i d=282879}$

[Article begins on next page]

The NIOZ Repository gives free access to the digital collection of the work of the Royal Netherlands Institute for Sea Research. This archive is managed according to the principles of the Open Access Movement, and the Open Archive Initiative. Each publication should be cited to its original source - please use the reference as presented.

When using parts of, or whole publications in your own work, permission from the author(s) or copyright holder(s) is always needed. 


\section{Understanding seagrass resilience in temperate systems: the importance of 2 timing of the disturbance}

3 Laura M. Soissons ${ }^{a^{*}}$, Baoquan $\mathrm{Li}^{\mathrm{b}}$, Qiuying $\mathrm{Han}^{\mathrm{b}}$, Marieke M. van Katwijk ${ }^{\mathrm{a}, \mathrm{c}}$, Tom Ysebaert ${ }^{\mathrm{a}}$, 4 Peter M.J. Herman ${ }^{a, c}$, Tjeerd J. Bouma ${ }^{a}$

$6{ }^{a}$ Spatial Ecology Department, Royal Netherlands Institute for Sea Research (NIOZ-Yerseke), P.O. Box $7 \quad 140,4400$ AC Yerseke, The Netherlands

$8{ }^{\mathrm{b}}$ Yantai Institute of Coastal Zone Research - Chinese Academy of Sciences (YIC-CAS), Chunhui Road 9 17, Laishan District, Shandong, China

c Department of Environmental Sciences, Institute for Wetland and Water Research, Faculty of Science, Radboud University Nijmegen, Nijmegen, Heijendaalseweg 135, 6525 AJ, The Netherlands

Corresponding author: laura.soissons@nioz.nl, Telephone: +31(0) 113 577445, Fax: +31(0) 113 573616

\section{Abstract}

Temperate seagrass meadows form valuable ecosystems in coastal environments and present a distinct seasonal growth. They are threatened by an increasing amount of stressors, potentially affecting their capacity to recover from disturbances. We hypothesized that their resilience to disturbances is affected by seasonal dynamics. Hence, we investigated the effect of the timing of the disturbance on seagrass Leaf Area Index (as a proxy for presence, or 'visible' status), recovery from disturbance (as a proxy for meadow resilience), and rhizome carbohydrates (as a proxy for longer term resilience) by a series of four disturbance-recovery field experiments spread over the growing season at two sites in Shandong Province, China. During the course of the growing season, we found the highest recovery at the start of the growing season, lowest recovery when Leaf Area Index peaked around mid-growing season, and intermediate recovery when Leaf Area Index decreased at the end of the growing season. Rhizome carbohydrates were not affected by disturbances during any of the four experimental periods and could not explain the low recovery during mid-growing season. The two sites differed in exposure and in the occurrence of incidents like a green tide and storms, which affected recovery. However, general patterns were similar; timing strongly influenced the 
indicator of meadow resilience and its correlation with presence during the two main seagrass growth phases. Our results emphasize the importance of carefully considering timing in the evaluation of seagrass resilience in temperate systems. Furthermore, our study implies that, to effectively protect seagrass beds, conservation management should aim at avoiding disturbances particularly during the peak of the growing season, when resilience is lowest.

Keywords: Indicators for ecosystem health; Resilience; Leaf Area Index; Recovery; Zostera marina; Temperate systems; Timing of disturbances

\section{Introduction}

Seagrasses are key marine angiosperms capable of creating extensive meadows through clonal growth (Hemminga \& Duarte 2000; Larkum et al., 2006). Their presence in intertidal as well as subtidal areas worldwide modifies the environment and creates suitable habitats for many benthic organisms and juvenile fish (Heck et al., 2003; Hughes et al., 2009). But seagrasses are globally increasingly threatened. Threats come mainly from anthropogenic activities and the subsequent environmental changes they induce (Hughes et al., 2009; Orth et al., 2006; Short and WyllieEcheverria, 1996; Waycott et al., 2009). It has been widely acknowledged that, over the last two decades, the combination of increasing disturbances and stresses has led to seagrass decline and occasionally sudden collapse. Recovery of such decline can be cumbersome, as seagrass meadows may act as bi-stable ecosystems, with the bare state being the alternative attractor (Carr et al., 2012, 2010; van der Heide et al., 2007). To be able to manage and to protect remaining seagrass meadows, it is important to gain fundamental insight in their resilience to disturbance.

Temperate seagrass ecosystems are known to have distinct seasonal growth and rhizome proliferation (Duarte 1989; Hemminga \& Duarte 2000; Larkum et al., 2006). The main mechanisms controlling the seasonal growth of seagrasses are changes in light intensity and temperature (Dennison, 1987; Duarte, 1991; Marbà et al., 2012; Ochieng et al., 2010; Olesen and Sand-jensen, 1993). Generally, plants start to grow in spring, until mid-summer when they reach their maximum shoot density and cover to build up their carbon reserve that allows them to overwinter and regrow the next year (Madsen, 1991). Then senescence starts in late summer with the release of seeds, leaves get thinner and shorter, and shoot density becomes lower (Hemminga and Duarte, 2000; 
Larkum et al., 2006). In winter, the vegetation is very sparse (Orth et al., 2012), only the below ground biomass - with limited leave presence - and seed banks remain until spring when new shoots grow again. To overcome the winter months, seagrass plants exploit the non-structural carbohydrate reserves gained during the summer period (Alcoverro et al., 1999; Govers et al., 2015; Lee et al., 2007; Madsen, 1991; Olivé et al., 2007). The amount of carbohydrates needed for seagrass survival over the winter periods depends on abiotic factors, i.e. temperature and light availability; but also on internal factors, such as respiration and growth (Alcoverro et al., 2001; Govers et al., 2015; Madsen, 1991). Chances of survival during winter thus depend on the plant's capacity to build up its carbon reserves during summer (Govers et al., 2015). Given these strong seasonal dynamics, it may be expected that seagrass resilience in temperate systems will be strongly affected by its growing season, making the recovery to a disturbance strongly sensitive to the period the disturbance occurs. It becomes essential to clearly pinpoint the specific time in their growth cycle when seagrass resilience would be either the most or least severely affected.

The resilience of a system is its ability to return to its initial form or state after a disturbance (Scheffer et al., 2009; van Nes and Scheffer, 2007). Resilience can be evaluated by looking at indicators of an ecosystem health status (for seagrasses e.g. cover, or multi parametric indexes such as ZONI, POMI, BIPO; Krause-Jensen et al., 2005; Marbà et al., 2012; García-Marín et al., 2013; Mascaró et al., 2013) or more dynamic early warning signals that indicate a potential critical transition of the system to another stable state, such as "critical slowing down" (Dakos et al., 2011; Scheffer et al., 2009). Critical slowing down is defined as "a phenomenon that happens when a monitored stable variable of the system returns more slowly to equilibrium after a small perturbation" (Dakos et al., 2011). It is evidenced, for instance, by a decrease in recovery rate when the system gets close to a transition point, and its resilience gets lower (Chisholm and Filotas, 2009; van Nes and Scheffer, 2007). Recent work shows that the choice of indicators (cover vs. critical slowing down) is important to consider, as they may provide an opposed response in their evaluation of seagrass health and resilience (Soissons et al., 2014). If resilience of temperate seagrass meadows would be affected by the different stages of the growing season, the indicators cover and critical slowing down may be expected to give different outcomes for seagrass resilience over the season.

In this study, we aim to assess the importance of timing over the growing season on seagrass resilience to disturbances. More specifically, we question whether seagrass recovery, as a measure for resilience and as a proxy for nearness of collapse ('critically slowing down', cf. Scheffer et al., 2009) and carbohydrates in the rhizomes, potentially representing a longer term resilience (cf. Govers et al., 2015) are dependent on the timing of a disturbance over the growing season. If the resilience differs along the growing season, our study will allow identifying the timing in the seagrass 
growth cycle that lead for better recovery and the timing when the beds are particularly vulnerable to disturbances. A manipulative experiment was implemented and repeated at different stages of the growing season on Zostera marina intertidal, seasonal stands at two sites in Shandong province, China, differing in their exposure to hydrodynamics and geographical setting (Figure 1). We measured Leaf Area Index (as a proxy for cover, representing seagrass presence or 'visible' status), relative recovery and carbohydrate content in rhizomes at each of the sequential, identical experiments.

\section{Material and methods}

\section{Study sites and experimental design}

In order to encompass the entire growing season, a series of 4 strictly identical resilience experiments were implemented at two sites within dense Zostera marina meadows (average densities ranging from 450 to 1080 shoots. $\mathrm{m}^{-2}$ at sites) but contrasting in their hydrodynamic conditions: Swan Lake, hereafter referred as Sheltered site (SS) and Dongchu Island, hereafter referred as Exposed site (ES) (Figure 1). Both sites are located in the Shandong province in China and are submitted to different pressures and stochastic events such as green tides during the summer season (at SS), storms (at ES) and human activities (at both sites). Hydrodynamics were not measured during the experiment, but the geographical situation (Figure 1) and wind fetch of both sites allowed us to define their relative exposure as sheltered versus exposed. The shallow lagoon was a relatively sheltered site (SS) compared to the open-sea system with a rocky shore and visible waves on the shore close to the meadow (i.e., exposed site; ES). This relative difference in exposure was confirmed by the difference in granulometry with a D50 of $119 \pm 26 \mu \mathrm{m}$ (fine sand) at the SS and a D50 of $478 \pm$ $121 \mu \mathrm{m}$ (medium sand) at the ES (see Soissons et al., 2014 for more information on both field sites).

In temperate systems, like for these two sites, the seagrass Zostera marina has a seasonal growth with shoots and seeds developing in spring until summer when, usually in July, they reach a maximum presence in terms of shoot density, size and cover (Zhang et al., 2014; and personal observations). In order to cover the growing season and to ascertain to capture the peak of seagrass presence at both sites, 4 sequential, independent and identical resilience experiments, with a slight overlap in timing for the 2 experiments during the expected peak seagrass cover (Zhang et al., 2014; 
personal observation), were implemented. The temporal resolution of the four resilience experiments was based on previous studies in the area, aiming to cover the entire growing season (Zhang et al., 2014; personal observation during 2012): i) experiment "Exp 1" at the beginning, when cover increases (9 May - 7 June 2013); ii) experiments "Exp 2" and "Exp 3" around the peak of the seagrass cover (7 June - 8 July and 26 June - 25 July 2013, respectively); and iii) experiment "Exp 4" at the end of the growing season presenting a decrease in cover (25 July - 24 August 2013) (for schematic representation see Figure 2). In each experiment, to assess seagrass resilience we measured recovery rates over a four week period; within this period we harvested four times: Harvest $1(\mathrm{H} 1)$, at the start of the experiment for control and initial plant parameters; Harvest $\mathrm{H} 2$ and $\mathrm{H} 3$, respectively two and three weeks after the beginning of the experiment; and Harvest $\mathrm{H} 4$, at the end of the experiment after four weeks from the start (Figure 2).

At each site, for each resilience experiment of four weeks, the procedure was identical: 30 plots (15 disturbed and 15 controls) were randomly allocated on a small area of apparent homogeneous seagrass density (average density of 450 to 1080 shoot. $\mathrm{m}^{-2}$ at SS and ES respectively) at start; different areas were selected for each of the four experiments (located at approx. $10 \mathrm{~m}$ distance from each other) to avoid working with an already sampled plot. From the 30 plots, 15 were randomly defined as controls and the other 15 as disturbed plots, leaving 5 replicates for control and 5 replicates for disturbed plots for each harvest time (i.e. Harvest $\mathrm{H} 2, \mathrm{H} 3$ and $\mathrm{H} 4$, after 2, 3 and 4 weeks, respectively) (Figure 2). As disturbance, circular gaps of $0.3 \mathrm{~m}$ diameter in the centre of each plot were created by clipping the leaves at the start of each resilience experiment, leaving the below ground and sheaths in place. Clipping was chosen to mimic grazing from birds (swans migrating in this region), or the effect of boat anchoring and shell collection by local fishermen, removing parts of the seagrass. It represents one type of disturbance experienced by seagrass meadows and was used, for this study, in order to get a general conceptual understanding of how timing of disturbances affect resilience. It also allowed us to investigate the short-term regrowth of disturbed plants. The size of a disturbance can affect the rate of recovery (Macreadie et al., 2014; Rasheed, 2004, 1999). For our experiments, $0.3 \mathrm{~m}$ diameter gaps were chosen from our experience with previous experiments in the same area as an optimal size for direct recovery measurements in a short-time period ( 4 weeks long experiments), to match the scale of the disturbance we mimic, and to minimize the overall impact of the experiment on the meadow (Soissons et al., 2014). Rhizomes around the disturbed plots were cut to limit recovery by colonization from the edges. Control plots were positioned similarly but remained untouched until harvest time (Figure 2). from the others: each starting with a disturbance (i.e. leaves clipping and subsequent clipped leaves 
biomass measures) with an additional harvest $(n=5)$ of full plant material (i.e. above and belowground material, sampled within the experimental area) that served as an initial measurement of Leaf Area Index (H1), then followed by 3 other harvest time ( $\mathrm{H} 2$ to $\mathrm{H} 4)$. Each resilience experiment lasted 4 weeks in total.

\section{Harvesting and analysis}

Seagrass harvesting: At the start of each resilience experiment, whole plant samples (i.e. including above and below-ground material) were harvested within the experimental area for initial morphological measurements $(\mathrm{H} 1, \mathrm{n}=5)$ in a surface of $0.07 \mathrm{~m}^{2}$. The leaves clipped in the $0.3 \mathrm{~m}$ diameter gaps to create the disturbance at the start of each resilience experiment $(n=15)$ were not used for morphological measures. Then, for each following harvest time $(\mathrm{H} 2, \mathrm{H} 3$ and $\mathrm{H} 4$ after 2,3 and 4 weeks, respectively), whole plants in 5 control and 5 disturbed plots were sampled in $0.3 \mathrm{~m}$ cores $\left(0.07 \mathrm{~m}^{2}\right)$ so that all plants in the $0.3 \mathrm{~m}$ diameter gaps were collected. After harvest, seagrasses were directly cleaned a first time in seawater in the field before being transported to the laboratory for measurements. All plants were carefully rinsed and cleaned in fresh water to remove epiphytes and any sediment left. The total number of shoots per sample was directly noted. Subsamples of 5 representative shoots per sample were randomly selected for morphodynamic measurements. Leave length, width and the number of leaves per shoot were measured for all replicates. Then, for the whole sample, leaves, rhizomes and roots were carefully separated, and subsequently freeze-dried for dry biomass measurements and carbohydrates analysis.

Leaf surface per shoot was calculated from the averaged values of morphodynamic measurements. The Leaf Area index of the standing seagrass meadow $\left(\mathrm{LAI}_{\text {standing }} ; \mathrm{m}^{2} \cdot \mathrm{m}^{-2}\right)$ was calculated as the product of leaf surface per shoot $\left(\mathrm{m}^{2}\right)$ times the shoot density $\left(\mathrm{m}^{-2}\right)$ from control plots. LAI was chosen as a proxy for seagrass cover, representing seagrass presence or 'visible' status, as quantifying stem density and leaf area provided us with a more precise and reproducible method than by making cover estimates. The $\mathrm{LAI}_{\text {regrowth }}\left(\mathrm{m}^{2} \cdot \mathrm{m}^{-2}\right)$ in the clipped gaps (i.e. disturbed plots) collected at each harvest time was used as a proxy for absolute recovery during the corresponding time period (i.e. harvest times: H2, after 2 weeks; H3, 3 weeks and H4, after 4 weeks). To enable comparison between sites for each harvest time, a relative recovery in terms of LAI was defined. We calculated the relative recovery $(\mathrm{RC} ; \%)$ by dividing $\mathrm{LAI}_{\text {regrowth(t) }}$ by $\mathrm{LAI}_{\text {standing(t) }}$ (equation 1 ). This relative recovery also provides us with a proxy for the evaluation of a potential critical slowing down (i.e. a slower recovery rate of a monitored variable after a disturbance), which is a measure of nearness to collapse (Chisholm and Filotas, 2009; Dakos et al., 2011; van Nes and Scheffer, 2007). Relative 
recovery was preferred over absolute recovery to estimate the recovery as a function of the growing season and because the experimental design already took recovery as a function of the growing season into account by being spread over the seasonal growth of plants. Indeed, we expected LAI to vary with time and thus to affect the relative recovery. We assumed that a lower relative recovery was indicative for a slower return of the system to its initial state and hence was representative of a critical slowing down in the system response to disturbance.

(1) $\quad \% R C_{(t)}=\frac{L A I_{\text {regrowth }(t)}}{L A I_{\text {standing }(t)}} \times 100$

Carbohydrate measurements: Freeze-dried and grinded rhizome samples were carefully shipped from China for carbohydrate measurements. Analyses of carbohydrates were completed at the Netherland Institute for Sea Research (NIOZ) in Yerseke; following a method developed after Yemm \& Willis (1954). First, soluble sugars -glucose, fructose and sucrose- were extracted out of the freeze-dried plant material by using an $80 \%$ ethanol solution. The residue was hydrolyzed with diluted hydrochloric acid (3\%HCL) to convert all the sugar compounds into carbohydrates. Subsequently the fraction was boiled at $100^{\circ} \mathrm{C}$ for 30 minutes. An Anthrone coloring reagent was added and the color intensity was measured at $625 \mathrm{~nm}$. By calibration with a d-glucose standard series, carbohydrate content in rhizomes was measured in $\mathrm{mg}$ carbohydrates per gram dry plant material (Yemm and Willis, 1954). All samples were measured in duplicate and a new calibration curve was prepared for every series of measurements.

Statistical analysis: The influence of three factors being 'timing' (i.e. the sequential, identical resilience experiments Exps 1 to 4), 'harvest time' and 'site' and their interactive effect on leaf surface per shoot, shoot density in controls and LAI (LAI $\left.\left.\right|_{\text {standing }}\right)$, absolute $\left(L A I_{\text {regrowth }}\right)$, relative recovery (\%RC) in disturbed plots were checked with a 3-way ANOVA (univariate) on SPSS (IBM ${ }^{\circledR}$ SPSS $^{\circledR}$ Statistics Version 21). For carbohydrate content in rhizome (only measured for the last harvest time, H4), the 3-way ANOVA included the effect of 'timing' (i.e. the sequential, identical resilience experiments Exps 1 to 4), 'site' and 'disturbance' and their interactive effect. Statistical differences between means were measured using the Tukey post-hoc tests. The correlation between indicators was tested with a linear regression model. Assumptions for regression as well as normality and homogeneity of the data were previously checked, along with interactions between factors. Data are presented as means $( \pm \mathrm{SE})$. 


\section{Results}

During the experimental period, two storms occurred at the exposed site, and two green tides at the sheltered site. During the green tide, algal cover (mainly Chaetomorpha linum) was up to $265 \mathrm{~g} \mathrm{DW} \cdot \mathrm{m}^{-2}$. Such events are common in the region (personal communication, Qiuying Han and local managers). No exceptional variations in the water temperature were noticed either in the winter before we implemented the experiment or during the growing season, although air temperatures in August were $2^{\circ} \mathrm{C}$ higher than normal (data obtained from the meteorological station in Rongcheng, Weihai, China).

\section{Leaf Area Index in relation to the growing season and across sites} as expected and in line with the growing season: LAl progressively increases from May until the beginning of July before decreasing in July-August (Figure $3 A$ and $3 B$ ). $\mathrm{LAI}_{\text {standing }}$ was similar to the $\mathrm{LAI}_{\text {standing }}$ in the preceding year at the same sites (values in 2012 between 6 and $10 \mathrm{~m}^{2} . \mathrm{m}^{-2}$; Soissons et al., 2014). Differences between sites and timing (i.e. differences between the sequential, identical resilience experiments Exp's 1 to 4) are strong (Table 1 and 2), as well as their interactive effect (Table 1): $\mathrm{LAI}_{\text {standing }}$ values are higher at site ES with values up to $12.6 \pm 1.5 \mathrm{~m}^{2} \cdot \mathrm{m}^{-2}$ at the top of the growing season (H1-Exp 3, Figure 3A) whereas the highest standing stock values at SS only reached $9.8 \pm 1.9 \mathrm{~m}^{2} \cdot \mathrm{m}^{-2}(\mathrm{H} 2$-Exp 3, Figure 3B). At neither site, no significant differences were found between the two resilience experiments implemented at the peak of growth season (Exp 2 and $\operatorname{Exp} 3$; Table 2). Other post-hoc tests indicated for the exposed site (Tukey: $p<0.01$ ) that LAI values increased from experiments $\operatorname{Exp} 1$ to Exp 2 and decreased at Exp 4 as compared to Exp 3. Similarly, at the sheltered site, Exp 3 presented significantly higher LAI $_{\text {standing }}$ values than Exp 1 (Tukey: $p=0.03$ ) and Exp 4 (Tukey: $p=0.013$ ). Harvest time did not show any statistical differences as such (Table 1), but a significant interactive effect between harvest time and resilience experiments is seen for $L A I_{\text {standing }}$ (Table 1). This interactive effect indicates an increasing $\mathrm{LAl}_{\text {standing }}$ between harvest times in the first experiment and decreasing $L A I_{\text {standing }}$ between harvest times in the last experiment, as is expected. 
Both absolute recovery ( $\mathrm{LAI}_{\text {regrowth; }}$ recovered LAI after leaves clipping) and relative recovery (\%RC) show an opposite trend to the standing stock with high values at the beginning (Exp 1), a decrease over the growing season, and a small increase towards the end of the growing season (Figure 3C and 3D; Table 2). Differences between sites and timing (i.e. differences between the sequential, identical resilience experiments Exp's 1 to 4) were significant on LAI $_{\text {regrowth }}$ and \%RC values as well as their interactive effect (Table 1 and 2). However, in all instances \%RC did not increase any further after the first harvest time (after 2 weeks), never reaching values higher than 25\%RC, meaning that the gaps might 'never' completely recover over the growing season (Figure $3 C$ and $3 D$ ). Post-hoc tests show that regrowth differed over time at the exposed site, with the first experiment being higher than the subsequent experiments (Tukey: $p<0.001$ ).

\section{Correlation between indicators (LAI vs. Relative recovery)}

In order to evaluate the correlation between the two indicators, data were compared according to two phases: a growth phase, where $L A I_{\text {standing }}$ is increasing at both sites, Exp 1 until the end of Exp 3 (from May until mid-July); and an end-of-season phase, evidenced by a decrease in $L A I_{\text {standing }}$ from the end of Exp 3 until the end of the last resilience experiment, Exp 4 (mid JulyAugust). No significant regression was found at SS. At ES, during the growth phase, a negative relationship was found between \%RC and $L A I_{\text {standing }}\left(R^{2}=0.61 ; p=0.013\right.$; Figure $\left.4 A\right)$. During the end-ofseason phase, this correlation was positive for $E S\left(R^{2}=0.67 ; p=0.042\right.$; Figure $\left.4 C\right)$.

Carbohydrate reserves were evaluated by measuring non-structural carbohydrates in rhizomes at the end of each experiment. The evolution of rhizome carbohydrate content differed between the two sites and along the entire experimental period but was not affected by disturbance (Table 3; Figure 5). Timing (i.e. comparing sequential, identical resilience experiments Exps'1 to 4) had an interactive effect with site, as well as with the disturbance treatment (Table 3; Figure 5). At $E S$, rhizome carbohydrate content showed an increase during the growth phase (between Exp 1 and $\operatorname{Exp} 2$, Tukey: $p<0.001$ ) and a decrease during the end-of-season phase (between $\operatorname{Exp} 3$ and $\operatorname{Exp} 4$, Tukey: $p=0.014$; Figure 5). The maximum carbohydrate content at ES was $56.3 \pm 0.97 \mathrm{mg} \cdot \mathrm{gDW}^{-1}$ at the peak of the growing season in control plots (Exp 2). At SS, rhizome carbohydrate content decreased over the growing season, with values declining almost 2 -fold from $80.3 \pm 12.7 \mathrm{mg}_{\mathrm{gDW}}{ }^{-1}$ 
for Exp 1 to $43.8 \pm 1.6 \mathrm{mg} . \mathrm{gDW}^{-1}$ at $\operatorname{Exp} 4$ in controls $(p=0.001$; Figure 5). No linear relationship was found between carbohydrate content (as an explanatory variable) and recovery.

\section{Discussion}

Seagrass presence and seasonal growth in temperate systems are controlled by abiotic variables such as light availability, hydrodynamics and temperatures (Marsh et al., 1986; Duarte 1991; Hemminga \& Duarte 2000) and their seasonal changes (Duarte, 1989, 1991; Hansen and Reidenbach, 2013; Olesen and Sand-jensen, 1993; Zharova et al., 2001). This seasonal growth of seagrasses is determinant for their winter survival and chances for seagrass expansion over time as they build up carbon reserves over the growing season (Alcoverro et al., 2001, 1999; Govers et al., 2015; Madsen, 1991). Present results emphasize the influence of different phases of the growing season on the resilience of temperate seagrass meadows against disturbance. In our series of identical experiments over the growing season at two sites, recovery from small-scale disturbances (i.e. above-ground biomass removal by clipping) was higher in the first experiments (at the beginning of the growing season) than in the experiments during the peak of the growing season, when seagrass cover had increased. This effect was found at both sites, despite their difference in exposure and in stochastic events (one site experiencing, green tides, the other site experiencing storms). Carbohydrates content in rhizomes varied between sites and over the growing season, but were not affected by the experimental small-scale disturbances applied throughout the growing season.

\section{The effect of timing on resilience in temperate systems}

According to the theoretical concepts of critical slowing down and resilience (Dakos et al., 2011; Scheffer et al., 2009; van Nes and Scheffer, 2007), a decrease in recovery rate indicates that the resilience against disturbances of the system is lowered and potential collapse is nearer. Our study shows that, at both research sites, recovery from a small-scale disturbance (clipping) is lowest during the peak of the growing season. Thus, when Leaf Area Index peaked, resilience of the meadows is indicated to be lowest. The slight increase in recovery at the end of the season would imply a higher resilience again at that stage. In general, this demonstrates the need to include a time dimension into the evaluation of resilience in seasonal systems. More specifically our findings imply 
for management that disturbances should be avoided during the peak of the growing season. It is however noted that a lower recovery at one specific moment in time may represent a low short-term resilience of the plants, but does not necessarily imply a reduced longer-term resilience. Also, it might be expected that repetitive disturbances would at some point lead to no recovery and drastically affect the plant's capacity to overwinter and regrow for the next season (Di Carlo et al., 2011).

Understanding timing effects on resilience is clearly particularly important in bi-stable seagrasses ecosystems (Carr et al., 2012, 2010; van der Heide et al., 2010), but may also apply to other bi-stable temperate ecosystems such as e.g. temperate shallow lakes (Scheffer et al., 2001, Scheffer and Van Nes 2007); salt-marshes (van Wesenbeeck et al., 2008); temperate reefs (Baskett and Salomon 2010); and temperate foodplains lakes (Chaparro et al., 2014). A time-scale in the evaluation of resilience and potential transition to another stable state (for instance, unvegetated) is to be considered at two levels: (i) Recovery might slow down in time as an indicator of a lower resilience (Chisholm and Filotas, 2009; Dakos et al., 2011; van Nes and Scheffer, 2007) but also (ii) might vary along the growth curve of the system as a function of its growth rate, and seasonal changes.

\section{The effect of timing on indicators of seagrass presence and resilience}

Indicators of seagrass presence (LAI) and resilience (recovery from small-scale disturbance, or Critical Slowing Down) showed an opposite response during the growth phase with recovery decreasing when the standing stock increased similar to results of Soissons et al. (2014). In contrast, both indicators were positively related at the end of the growing season at the exposed site, which to our knowledge was not observed before. Present results are opposite to results from tropical seagrasses measured by de longh et al. (1995), where a full recovery was observed during the wet season (when biomass/cover increases) and no recovery was measured during the dry season after dugong grazing (i.e. mostly above-ground removal). This difference could be explained by this seagrass population being close to collapse, or, more likely, by the stronger role of timing during the growing season and more extreme changes in abiotic variables in temperate systems (Baskett and Salomon, 2010; Chaparro et al., 2014).

During an event of green tide at the sheltered site, rather common in that region, with green algae (mainly Chaetomorpha linum) covering the seagrasses, the Leaf Area Index in the controls was less affected than the disturbed plants, though lower than at the exposed site. This implies that 
stress reduces resilience, which is in line with the CSD-theory (Dakos et al., 2011; Scheffer et al., 2009; van Nes and Scheffer, 2007). It might be speculated that the plants, under disturbance and additional stress (green tides/algae shading) might experience a trade-off between recovering from the disturbance through re-growth and maintaining their below-ground stock for better chances to survive the winter period. Such trade-off might explain the difference in recovery rates, although small at both sites at the peak of growth, between ES and SS. Most importantly, the timing of the disturbance and the seasonal changes in seagrass presence and biomass played an overruling role on both resilience and capacity to recover, regardless of site and stress level.

\section{Seagrass resilience in relation to carbohydrate content in rhizomes}

Surprisingly, in our experiment, rhizome carbohydrate content did not show any change after disturbances, whereas differences between sites were present. At the sheltered site, rhizome carbohydrate content remained high in disturbed plots even though recovery was very low or close to 0 . During a green tide with large algae cover at the sheltered site, carbohydrates had the tendency to decrease but only in controls as has been observed in Spain on Zostera noltii plants shaded by the macroalgae Ulva rigida (Brun et al., 2003). Our results suggest that the plants do not use the carbohydrates stored in the rhizomes for recovery from small-scale disturbances in summer.

In temperate systems, plants use carbon reserves such as carbohydrates stored in rhizomes to cope with winter stresses and regrow next season (Alcoverro et al., 1999; Govers et al., 2015; Madsen, 1991). A higher standing stock-and thus recovered stock- would ensure a better chance for winter survival, and carbon reserves can serve as an indicator for winter survival, as a colder winter might greatly reduce their carbohydrate reserves and thus their resilience (Govers et al., 2015). Our study did not investigate the link between current and past growing season, however no exceptional variations in the water temperature were noticed either in the winter before we implemented the experiment or during the growing season. Overall our results hence suggest that small-scale disturbances during the growing season do not affect winter survival.

\section{Conclusion and implications for seagrass conservation and management}

Seagrasses worldwide form essential ecosystems in the coastal landscape. Unfortunately, they are submitted to various and repetitive stresses, mostly due to the increasing development of anthropogenic activities (Orth et al., 2006; Waycott et al., 2009; Unsworth et al., 2014) as well as 
effects of climate change. A growing number of seagrass meadows are nowadays monitored and submitted to management plans, as part of Marine Protect Area (MPA) schemes for instance, to conserve them (La Manna et al., 2015). In economically strongly developing countries, as e.g. China, land reclamation and the intensive use of coastal areas are still on-going and increase at high rates (Ma et al., 2014). Our finding that both seagrass sites show a low capacity to recover over their seasonal growth (i.e. lower than 50\%) is illustrative of the threats to seagrass in such rapidly developing areas, particularly considering the almost complete absence of other seagrass beds in a wide area around them (Yellow river mouth, personal observation).

In our study, the seasonal changes in standing stock and growth, as well as recovery capacity, were more likely due to spring and abiotic fluctuations than to carbon reserves. Hence, carbohydrate content in rhizomes, in our experiment, did not form a good predictor for the plant's capacity to recover over their growing season. Our results illustrate the need to pinpoint the time in the growing season when the seagrass response to a disturbance would be the least or the most damaging for their short-term resilience. The knowledge of seasonal changes in presence but also in the resilience of keystone ecosystems such as seagrasses becomes then essential in order to preserve them from future collapse. For instance, our study shows that a disturbance at the peak of growth could result in a lower recovery than at the beginning of the growing season. This might thus reduce their net production and lead to their decline. Henceforth, it is essential to carefully consider the timing at which a potentially disturbing activity such as e.g. dredging or trawling is carried out, as timing was shown to have considerable impacts on recovery rates, implying a reduced resilience.

Overall, these results provide conceptual insights that may help management of seagrass meadows, for conservation purposes, especially with respect to the importance of regulating the timing of human disturbances in coastal areas. Considering the seasonal growth and changes of coastal ecosystems is essential, in order to better preserve them and to prevent their potential collapse. Indicators are needed to evaluate resilience, but the effect of timing must be considered as it forms a fundamental factor to integrate for both the use of indicators and the evaluation of resilience, in seagrass as for any other seasonal systems.

\section{Acknowledgments}


This study was conducted as part of the NSFC-NWO "Water ways, Harbours, Estuaries and Coastal Engineering" scheme and was co-supported by the National Natural Science Foundation of China (No. NSFC41061130543) and the Netherlands Organisation for Scientific Research (No. 843.10.003). We thank the local managers from Swan Lake and Dongchu Island for their interest and support in implementing the experiments. We are also grateful to the students from the YIC-CAS for their help and time during field experiments and measurements done in China; to Marco Houtekamer, Peter van Breugel and Benjamin Moerenhout for their help and contribution to the carbohydrate analysis in the Netherlands. We would like to thank two anonymous reviewers for their comments and suggestions on an earlier version of the manuscript.

\section{References}

Alcoverro, T., Manzanera, M., Romero, J., 2001. Annual metabolic carbon balance of the seagrass Posidonia oceanica: the importance of carbohydrate reserves. Mar. Ecol. Prog. Ser. 211, 105116. doi:10.3354/meps211105

Alcoverro, T., Zimmerman, R.C., Kohrs, D.G., Alberte, R.S., 1999. Resource allocation and sucrose mobilization in light-limited eelgrass Zostera marina. Mar. Ecol. Prog. Ser. 187, 121-131.

Baskett, M.L., Salomon, A.K., 2010. Recruitment facilitation can drive alternative states on temperate reefs. Ecology 91, 1763-1773. doi:10.1890/09-0515.1

Brun, F.G., Hernández, I., Vergara, J.J., Pérez-Lloréns, J.L., 2003. Growth, carbon allocation and proteolytic activity in the seagrass Zostera noltii shaded by Ulva canopies. Funct. Plant Biol. 30, 551-560. doi:10.1071/FP03010

Carr, J.A., D’Odorico, P., McGlathery, K.J., Wiberg, P. I, 2010. Stability and bistability of seagrass ecosystems in shallow coastal lagoons: Role of feedbacks with sediment resuspension and light attenuation. J. Geophys. Res. 115, G03011. doi:10.1029/2009JG001103

Carr, J.A., D'Odorico, P., McGlathery, K.J., Wiberg, P. I, 2012. Modeling the effects of climate change on eelgrass stability and resilience: future scenarios and leading indicators of collapse. Mar. Ecol. Prog. Ser. 448, 289-301. doi:10.3354/meps09556

Chaparro, G., Fontanarrosa, M.S., Schiaffino, M.R., de Tezanos Pinto, P., O’Farrell, I., 2014. Seasonaldependence in the responses of biological communities to flood pulses in warm temperate floodplain lakes: implications for the "alternative stable states" model. Aquat. Sci. 579-594. doi:10.1007/s00027-014-0356-5

Chisholm, R.A., Filotas, E., 2009. Critical slowing down as an indicator of transitions in two-species models. J. Theor. Biol. 257, 142-9. doi:10.1016/j.jtbi.2008.11.008

Dakos, V., Kéfi, S., Rietkerk, M., van Nes, E.H., Scheffer, M., 2011. Slowing down in spatially patterned ecosystems at the brink of collapse. Am. Nat. 177, E153-66. doi:10.1086/659945

de longh, H.H., Wenno, B.J., Meelis, E., 1995. Seagrass distribution and seasonal biomass changes in relation to dugong grazing in the Moluccas, East Indonesia. Aquat. Bot. 50, 1-19. 
Dennison, W.C., 1987. Effects of light on seagrass photosynthesis, growth and depth distribution. Aquat. Bot. 27, 15-26. doi:10.1016/0304-3770(87)90083-0

Di Carlo, G., Benedetti-Cecchi, L., Badalamenti, F., 2011. Response of Posidonia oceanica growth to dredging effects of different magnitude. Mar. Ecol. Prog. Ser. 423, 39-45.

Duarte, C., 1989. Temporal biomass variability and production/biomass relationships of seagrass communities . Mar. Ecol. Prog. Ser. 51, 269-276. doi:10.3354/meps051269

Duarte, C.M., 1991. Seagrass depth limits. Aquat. Bot. 40, 363-377. doi:10.1016/03043770(91)90081-F

García-Marín, P., Cabaço, S., Hernández, I., Vergara, J.J., Silva, J., Santos, R., 2013. Multi-metric index based on the seagrass Zostera noltii (ZoNI) for ecological quality assessment of coastal and estuarine systems in SW Iberian Peninsula. Mar. Pollut. Bull. 68, 46-54. doi:10.1016/j.marpolbul.2012.12.025

Govers, L.L., Suykerbuyk, W., Hoppenreijs, J.H.T., Giesen, K., Bouma, T.J., van Katwijk, M.M., 2015. Rhizome starch as indicator for temperate seagrass winter survival. Ecol. Indic. 49, 53-60. doi:10.1016/j.ecolind.2014.10.002

Hansen, J.C.R., Reidenbach, M. a., 2013. Seasonal Growth and Senescence of a Zostera marina Seagrass Meadow Alters Wave-Dominated Flow and Sediment Suspension Within a Coastal Bay. Estuaries and Coasts 36, 1099-1114. doi:10.1007/s12237-013-9620-5

Heck, K.L., Hays, G., Orth, R.J., 2003. Critical evaluation of the nursery role hypothesis for seagrass meadows. Mar. Ecol. Prog. Ser. 253, 123-136.

Hemminga, M.A., Duarte, C.M., 2000. Seagrass Ecology. Cambridge university Press.

Hughes, A.R., Williams, S.L., Duarte, C.M., Heck, K.L., Waycott, M., 2009. Associations of concern: declining seagrasses and threatened dependent species. Front. Ecol. Environ. 7, 242-246. doi:10.1890/080041

Krause-Jensen, D., Greve, T.M., Nielsen, K., 2005. Eelgrass as a Bioindicator Under the European Water Framework Directive. Water Resour. Manag. 19, 63-75. doi:10.1007/s11269-005-0293-0

La Manna, G., Donno, Y., Sarà, G., Ceccherelli, G., 2015. The detrimental consequences for seagrass of ineffective marine park management related to boat anchoring. Mar. Pollut. Bull. 90, 160166. doi:10.1016/j.marpolbul.2014.11.001

Larkum, A.W.D., Orth, R.J., Duarte, C.M., 2006. Seagrasses: Biology, Ecology and Conservation. Springer.

Lee, K.-S., Park, S.R., Kim, Y.K., 2007. Effects of irradiance, temperature, and nutrients on growth dynamics of seagrasses: A review. J. Exp. Mar. Bio. Ecol. 350, 144-175. doi:10.1016/j.jembe.2007.06.016

Ma, Z., Melville, D.S., Liu, J., Chen, Y., Yang, H., Ren, W., Zhang, Z., Piersma, T., Li, B., 2014. Rethinking China's new great wall. Science (80-. ). 346, 912-914. doi:10.1126/science.1257258

Macreadie, P.I., York, P.H., Sherman, C.D.H., 2014. Resilience of Zostera muelleri seagrass to smallscale disturbances: the relative importance of asexual versus sexual recovery. Ecol. Evol. n/an/a. doi:10.1002/ece3.933

Madsen, J.D., 1991. Resource allocation at the individual plant level. Aquat. Bot. 41, 67-86. doi:10.1016/0304-3770(91)90039-8 
Marbà, N., Krause-Jensen, D., Alcoverro, T., Birk, S., Pedersen, A., Neto, J.M., Orfanidis, S., Garmendia, J.M., Muxika, I., Borja, A., Dencheva, K., Duarte, C.M., 2012. Diversity of European seagrass indicators: patterns within and across regions. Hydrobiologia 704, 265-278. doi:10.1007/s10750-012-1403-7

Marsh, J. a, Dennison, W.C., Alberte, R.S., Alberte, S., 1986. Effects of temperature on photosynthesis and respiration in eelgrass (Zostera marina L.). J. Exp. Mar. Bio. Ecol. 101, 257-267. doi:10.1016/0022-0981(86)90267-4

Mascaró, O., Alcoverro, T., Dencheva, K., Díez, I., Gorostiaga, J.M., Krause-Jensen, D., Balsby, T.J.S., Marbà, N., Muxika, I., Neto, J.M., Nikolić, V., Orfanidis, S., Pedersen, A., Pérez, M., Romero, J., 2013. Exploring the robustness of macrophyte-based classification methods to assess the ecological status of coastal and transitional ecosystems under the Water Framework Directive. Hydrobiologia 704, 279-291. doi:10.1007/s10750-012-1426-0

Ochieng, C.A., Short, F.T., Walker, D.I., 2010. Photosynthetic and morphological responses of eelgrass (Zostera marina L.) to a gradient of light conditions. J. Exp. Mar. Bio. Ecol. 382, 117-124. doi:10.1016/j.jembe.2009.11.007

Olesen, B., Sand-jensen, K., 1993. Seasonal acclimatization of eelgrass Zostera marina growth to light. Mar. Ecol. Prog. Ser. 94, 91-99.

Olivé, I., Brun, F.G., Vergara, J.J., Pérez-Lloréns, J.L., 2007. Effects of light and biomass partitioning on growth, photosynthesis and carbohydrate content of the seagrass Zostera noltii Hornem. J. Exp. Mar. Bio. Ecol. 345, 90-100. doi:10.1016/j.jembe.2007.02.008

Orth, R.J., Carruthers, T.J.B., Dennison, W.C., Duarte, C.M., Fourqurean, J.W., Heck Jr, K.L., Hughes, A.R.R., Kendrick, G.A., Kenworthy, W.J., Olyarnik, S., Short, F.T., Waycott, M., Williams, S.L., 2006. A Global Crisis for Seagrass Ecosystems. Bioscience 56, 987-996. doi:10.1641/0006$3568(2006) 56$

Orth, R.J., Moore, K.A., Marion, S.R., Wilcox, D., Parrish, D., 2012. Seed addition facilitates eelgrass recovery in a coastal bay system. Mar. Ecol. Prog. Ser. 448, 177-195. doi:10.3354/meps09522

Rasheed, M.A., 1999. Recovery of experimentally created gaps within a tropical Zostera capricorni (Aschers.) seagrass meadow, Queensland Australia. J. Exp. Mar. Bio. Ecol. 235, 183-200. doi:10.1016/S0022-0981(98)00158-0

Rasheed, M.A., 2004. Recovery and succession in a multi-species tropical seagrass meadow following experimental disturbance: the role of sexual and asexual reproduction. J. Exp. Mar. Bio. Ecol. 310, 13-45. doi:10.1016/j.jembe.2004.03.022

Scheffer, M., Bascompte, J., Brock, W. a, Brovkin, V., Carpenter, S.R., Dakos, V., Held, H., van Nes, E.H., Rietkerk, M., Sugihara, G., 2009. Early-warning signals for critical transitions. Nature 461, 53-9. doi:10.1038/nature08227

Scheffer, M., Carpenter, S., Foley, J. a, Folke, C., Walker, B., 2001. Catastrophic shifts in ecosystems. Nature 413, 591-6. doi:10.1038/35098000

Scheffer, M., Van Nes, E.H., 2007. Shallow lakes theory revisited: Various alternative regimes driven by climate, nutrients, depth and lake size. Hydrobiologia 584, 455-466. doi:10.1007/s10750007-0616-7

Short, F.T., Wyllie-Echeverria, S., 1996. Natural and human-induced disturbance of seagrasses. Environ. Conserv. 23, 17-27.

Soissons, L.M., Han, Q., Li, B., van Katwijk, M.M., Ysebaert, T., Herman, P.M.J., Bouma, T.J., 2014. Cover versus recovery: Contrasting responses of two indicators in seagrass beds. Mar. Pollut. 
Unsworth, R.K.F., van Keulen, M., Coles, R.G., 2014. Seagrass meadows in a globally changing environment. Mar. Pollut. Bull. 83, 383-386. doi:10.1016/j.marpolbul.2014.02.026

van der Heide, T., van Nes, E.H., Geerling, G.W., Smolders, A.J.P., Bouma, T.J., van Katwijk, M.M., 2007. Positive Feedbacks in Seagrass Ecosystems: Implications for Success in Conservation and Restoration. Ecosystems 10, 1311-1322. doi:10.1007/s10021-007-9099-7

van der Heide, T., van Nes, E.H., van Katwijk, M.M., Scheffer, M., Hendriks, A.J., Smolders, A.J.P., 2010. Alternative Stable States Driven by Density-Dependent Toxicity. Ecosystems 13, 841-850. doi:10.1007/s10021-010-9358-x

van Nes, E.H., Scheffer, M., 2007. Slow recovery from perturbations as a generic indicator of a nearby catastrophic shift. Am. Nat. 169, 738-47. doi:10.1086/516845

van Wesenbeeck, B.K., van de Koppel, J., Herman, P.M.J., Bertness, M.D., van der Wal, D., Bakker, J.P., Bouma, T.J., 2008. Potential for Sudden Shifts in Transient Systems: Distinguishing Between Local and Landscape-Scale Processes. Ecosystems 11, 1133-1141. doi:10.1007/s10021-0089184-6

Waycott, M., Duarte, C.M., Carruthers, T.J.B., Orth, R.J., Dennison, W.C., Olyarnik, S., Calladine, A., Fourqurean, J.W., Heck, K.L.J., Hughes, A.R., Kendrick, G.A., Kenworthy, W.J., Short, F.T., Williams, S.L., 2009. Accelerating loss of seagrasses across the globe threatens coastal ecosystems. Proc. Natl. Acad. Sci. U. S. A. 106, 12377-12381. doi:10.1073/pnas.0905620106

Yemm, E.W., Willis, A.J., 1954. The estimation of carbohydrates in plant extracts by anthrone. Biochem. J. 57, 508-514.

Zhang, P.D., Liu, Y.S., Guo, Do., Li, W.T., Zhang, Q., 2014. Seasonal Variation in Growth, Morphology, and Reproduction of Eelgrass Zostera marina on the Eastern Coast of the Shandong Peninsula, China. J. Coast. Res. doi:10.2112/JCOASTRES-D-14-00117.1

Zharova, N., Sfriso, A., Voinov, A., Pavoni, B., 2001. A simulation model for the annual fluctuation of Zostera marina biomass in the Venice lagoon. Aquat. Bot. 70, 135-150. doi:10.1016/S03043770(01)00151-6 
566 Tables

567

Table 1: Three-factors ANOVA p-values of the effect of resilience experiments representing timing (Exps' 1 to 4), harvest

\begin{tabular}{|c|c|c|c|}
\hline & $\mathbf{L A l}_{\text {standing }}$ & $\mathrm{LAI}_{\text {regrowth }}$ & $\% R C$ \\
\hline Timing & $<0.001^{* * *}$ & $<0.001^{* * *}$ & $<0.001^{* * *}$ \\
\hline Harvest time & 0.273 & 0.995 & 0.394 \\
\hline Site & $<0.001^{* * *}$ & $<0.001^{* * *}$ & $0.015^{* * *}$ \\
\hline Timing* Harvest time & $0.004^{* * *}$ & 0.742 & 0.321 \\
\hline Timing* Site & $0.003^{* * *}$ & $<0.001^{* * *}$ & $0.018^{* * *}$ \\
\hline Harvest time* Site & 0.667 & 0.462 & 0.283 \\
\hline $\begin{array}{l}\text { Timing }{ }^{*} \text { Harvest time* } \\
\text { Site }\end{array}$ & $0.002^{* * *}$ & 0.261 & 0.714 \\
\hline
\end{tabular}

571 
Table 2: p-values, following post-hoc Tukey HSD test (from 3-factor ANOVA) on the effect of timing (i.e. differences

$\begin{array}{ccccc} & & \mathrm{LAI}_{\text {standing }} & \mathrm{LAI}_{\text {regrowth }} & \text { \%RC } \\ \text { Exp 1 } & \text { Exp 2 } & 0.001^{* * *} & <0.001^{* * *} & <0.001^{* * *} \\ & \text { Exp 3 } & 0.017^{* *} & 0.005^{* * *} & 0.003^{* * *} \\ & \text { Exp 4 } & 0.01^{* * *} & <0.001^{* * *} & 0.005^{* * *} \\ & & & & \\ \text { Exp 2 } & \text { Exp 3 } & 0.839 & 0.801 & 0.847 \\ & \text { Exp 4 } & <0.001^{* * *} & 0.972 & 0.637\end{array}$

$\begin{array}{lllll}\text { Exp } 3 & \operatorname{Exp} 4 & <0.001^{* * *} & 0.552 & 0.988\end{array}$

579

580

581

582

583

Table 3: Three-factors ANOVA p-values of the effect of site, timing (i.e. resilience experiments (Exps'1 to 4), disturbance and their interactive effect for the dependent variables carbohydrate content in rhizomes at the end of each resilience experiment.

\begin{tabular}{lc}
\hline \hline Site & $\begin{array}{c}\text { Carbohydrate content } \\
\text { in rhizomes } \\
<0.001^{* * *}\end{array}$ \\
Timing & $0.003^{\star * *}$ \\
Disturbance & 0.433 \\
Site*Timing & $<0.001^{* * *}$ \\
Site*Disturbance & 0.549 \\
Timing*Disturbance & $0.049^{* *}$ \\
Site*Timing*Disturbance & 0.407 \\
\hline \hline
\end{tabular}


$587 \quad$ Figures

588



589

590

Figure 1: Satellite images of the two study sites in the Shandong province, China.

591 


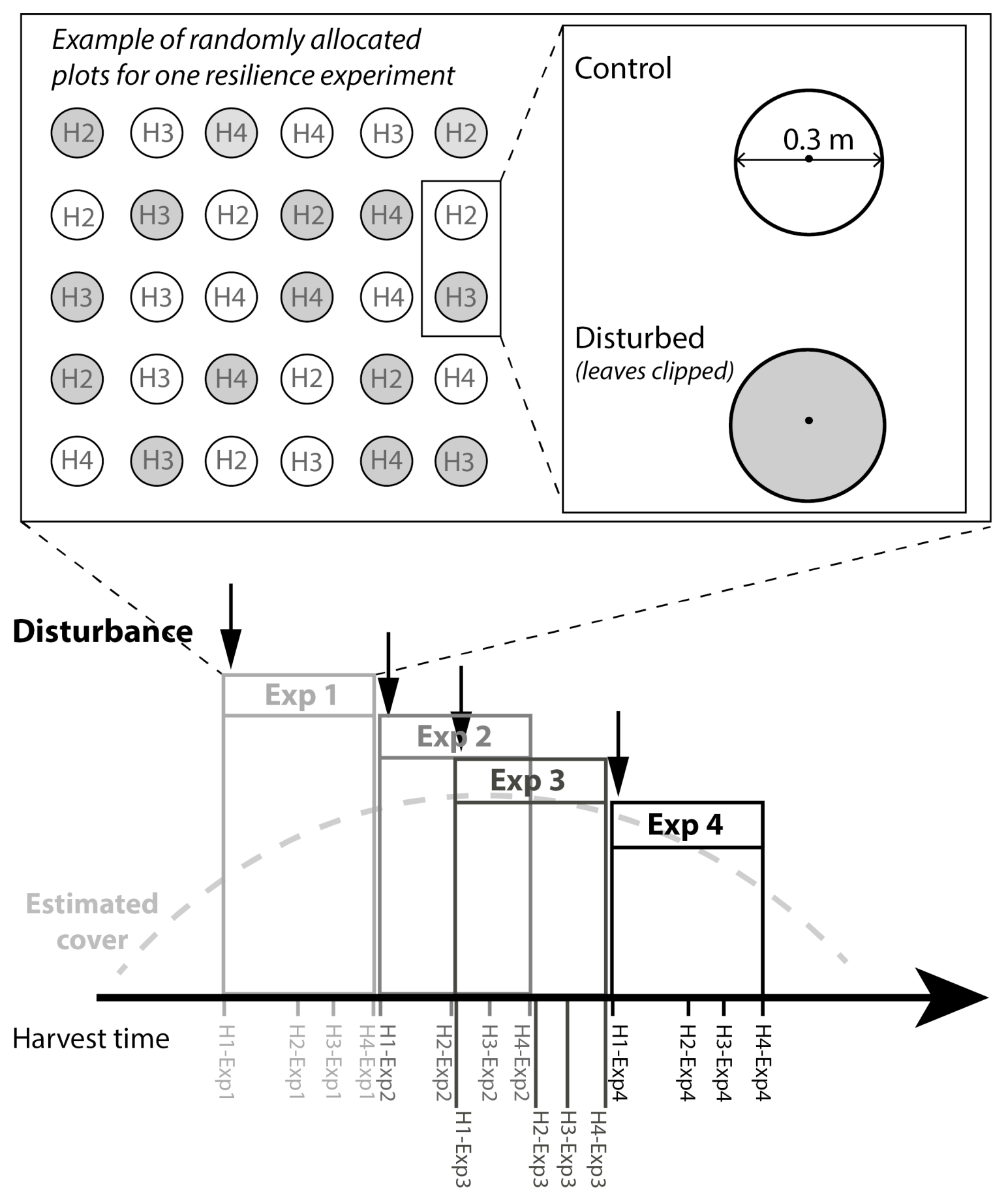

Figure 2: Diagram of the experimental design and time frame for all resilience experiments. The upper diagram shows the random distribution of the plots according to their treatments (empty circles represent the control plots, grey circles represent the disturbed plots) and the different harvest times. In the lower diagram, the four independent, sequential, identical resilience experiments to study timing are represented along the time line and referred to as Exp 1 to 4 . The slight overlap between Exp 2 and Exp 3 was designed to better capture the peak of the growing season. The downward black arrows at the start of each resilience experiment represent the disturbance created by clipping the leaves. The four harvest times ( $\mathrm{H} 1$ to $\mathrm{H} 4)$ are represented per resilience experiment along the timeline. $\mathrm{H} 1$ was done at the start of each resilience experiment within the experimental area for control samples only, and thus is not represented in the upper diagram. 

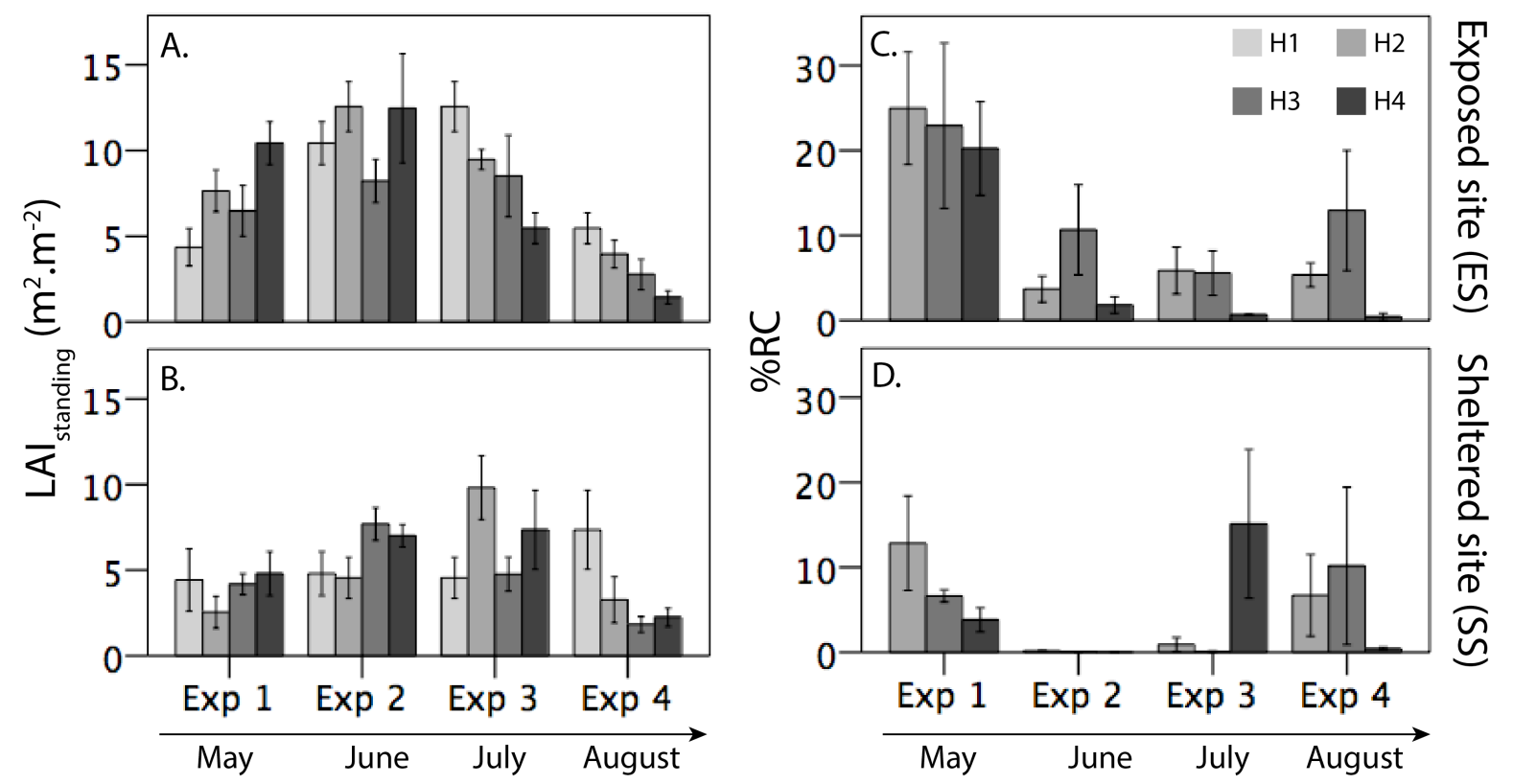

Figure 3: Leaf Area Index of the standing stock (LAI ${ }_{\text {standing }}$ in $\mathrm{m}^{2} \cdot \mathrm{m}^{-2}$ (A. and B.; data based on control plots) and Relative recovery (Critical slowing down) in \%RC (C. and D.; data based on disturbed plots) at both sites (Exposed site (ES) for A. 606 and C., and Sheltered site (SS) for B. and D.) at the different resilience experiment (Exp) and harvest times (H). 

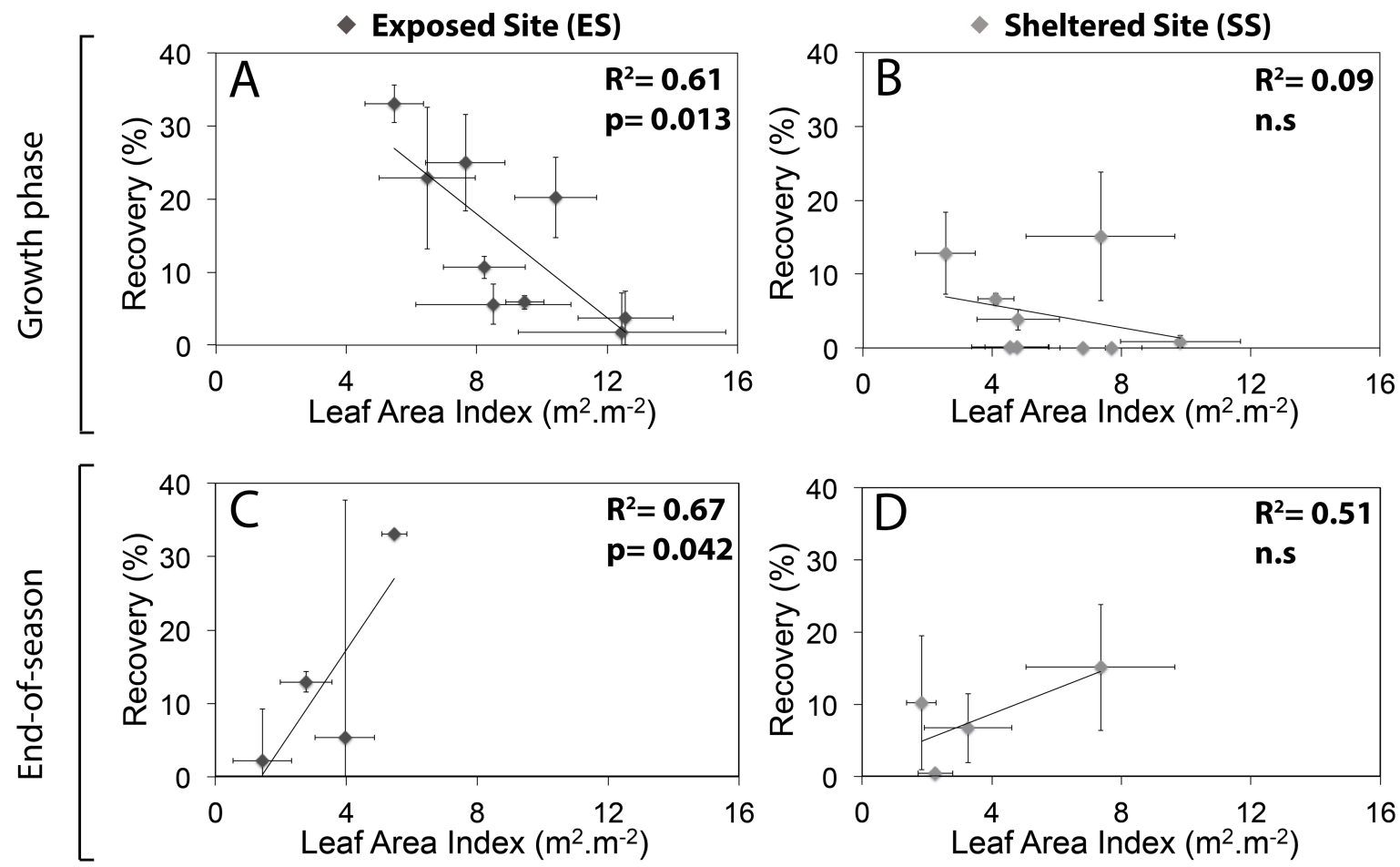

Figure 4: Correlation between indicators: Relative recovery (\%RC) as a function of Leaf Area Index $\left(\mathrm{LAI}_{\text {standing }} ; \mathrm{m}^{2} \cdot \mathrm{m}^{-2}\right)$ in control plots. A and B: Correlation during the growth phase at the Exposed site ES (dark markers) and Sheltered site SS (grey markers) respectively; C and D: Correlation during the End-of-season phase at ES and SS respectively. The growth phase corresponds to the period from May until mid-July; the end-of-season phase corresponds to the period from end of July till end of August. Bars represent standard errors for both indicators. $R^{2}$ and $p$-values are displayed on each graph $616 \quad(\mathrm{n} . \mathrm{s}$ for when $\mathrm{p}>0.05)$ 


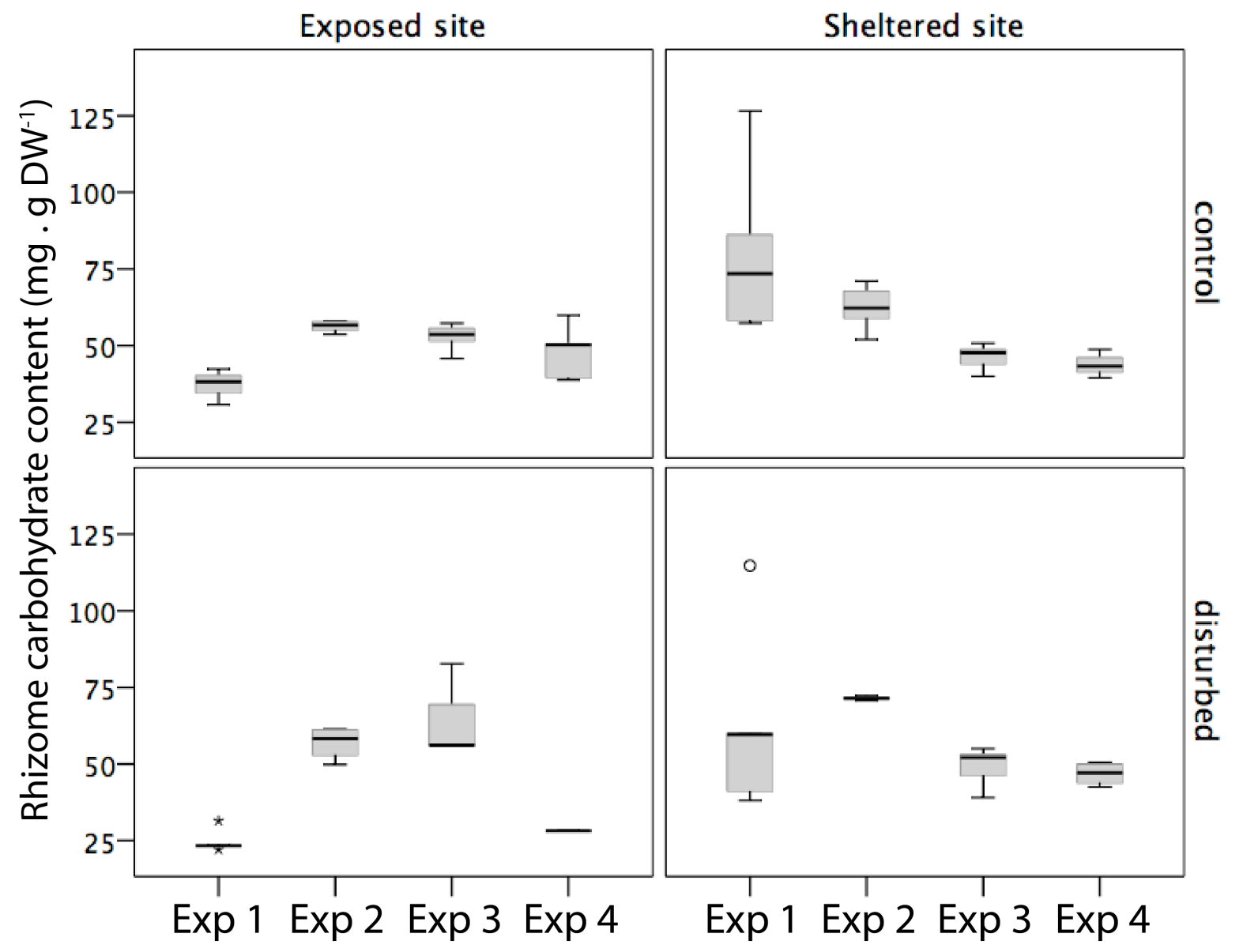

Figure 5: Boxplots representing the rhizome carbohydrate content in $\mathrm{mg} \mathrm{gDW}^{-1}$ at the end of each resilience experiments 